\title{
ROBOCODE COMO FERRAMENTA DE ENSINO DE PROGRAMAÇÃO EM CURSO DE SISTEMAS DE INFORMAÇÃO
}

\author{
ROBOCODE AS PROGRAMMING TEACHING TOOL IN COURSE OF \\ INFORMATION SYSTEMS
}

Ernane Rosa Martins

Instituto Federal de Educação, Ciência e Tecnologia de Goiás.

Ernane.martins@ifg.edu.br

RESUMO - Esse artigo tem como propósito descrever uma experiência do uso da ferramenta Robocode no apoio ao ensino de programação, a fim de estimular o interesse em programação pelos alunos do curso de Sistemas de Informação do Instituto Federal de Goiás. A experiência consistiu na organização e realização de um campeonato de Robocode. Ao final deste foi desenvolvida uma pesquisa com os alunos participantes em relação à atividade realizada, a fim de verificar os relatos destes em relação à ferramenta aplicada. Por fim são apresentados os resultados encontrados, que segundo os alunos, o Robocode pode ser uma ferramenta adequada para utilização na disciplina de programação, tornando-a mais divertida e interessante, por meio de atividades práticas reais. Os resultados observados incluem ainda desenvolvimento de novas habilidades e raciocínio logico, aumento da capacidade, aprimoramento do conhecimento, incentivo e motivação aos estudos e trabalho em equipe.

Palavras-chave: Robocode; ensino; programação.

ABSTRACT - This article aims to describe an experience of using Robocode tool to support programming education in order to stimulate interest in programming for students of the Federal Institute of Goiás Information Systems. The experience was the organization and implementation of one Robocode championship. At the end of this it was developed a survey of participating students in relation to the activity carried out in order to verify the reports of these in relation to the applied tool. Finally we present the results found that according to the students, the Robocode can be an appropriate tool to use in programming discipline, making it more fun and interesting, through real practical activities. The observed results include development of new skills and logical reasoning, increased capacity, improvement of knowledge, encouragement and motivation to study and teamwork.

Keywords: Robocode; teaching; programming. 


\section{INTRODUÇÃO}

Um problema enfrentado por vários países incluindo o Brasil são os altos índices de evasão e reprovação nos cursos da área da computação e informática (DIAS E SERRAO, 2014). A evasão estudantil no ensino superior é um problema que afeta o resultado dos sistemas educacionais, demandando desperdícios sociais, acadêmicos e econômicos. A evasão é uma fonte de ociosidade de professores, funcionários, equipamentos e espaço físico (LOBO ROBERTO, 2007).

Segundo Freitas e Piva Jr (2011), com base nos dados do Instituto Nacional de Estudos e Pesquisas Educacionais Anísio Teixeira (INEP), no Brasil dos 40.435 estudantes ingressantes em cursos de computação no ano de 2008, apenas 35,1\% conseguiram concluir seus cursos.

Atualmente em várias universidades tais como na Universidade Federal de Pernambuco e na Universidade de Tecnologia da Informação de Copenhagen, estão sendo utilizadas diversas maneiras para facilitar o ensino-aprendizagem (EA) nos ambientes educacionais, como por exemplo o uso de jogos educacionais. Uma das principais tarefas que os educadores enfrentam é o de motivar os alunos a realizarem as suas melhores habilidades. Um método motivador de alunos é o exercício baseado em jogos
(AMARAL; SILVA; PANTALEÃO, 2015; MORAN, 2009; MORAN, 2005; SAVI E ULBRICHT, 2008).

$\mathrm{Na}$ área da computação, é comum que alunos apresentem dificuldades nas disciplinas de programação, sendo isso um obstáculo a ser superado (LONG, 2007). Uma das dificuldades de aprender programação reside no fato de ser necessário aprender, em um curto espaço de tempo, conceitos diversos e desenvolver habilidades específicas como abstração e pensamento computacional (BITTENCOURT et al., 2013).

Moran, Masetto e Behrens, (2007, p. 11) afirmam que aulas baseadas no método expositivo, onde o professor é o retentor do conhecimento e o aluno é o receptor estão ultrapassadas. A educação para o século XXI deve ser pensada para os estudantes do século XXI (FRANÇA; SILVA; AMARAL, 2013). As aulas devem visar à utilização de metodologias de ensino inovadoras e transformadoras, com foco na busca pela participação e o interesse do aluno e pela integração da teoria e prática (AMARAL, 2004; MORAN, 2005). Nesse processo, o professor continua tendo um papel fundamental, não como transmissor do conhecimento, mas sim como mediador no acesso e organização dos processos (MORAN, 2009).

Ao aliar conteúdo educacional à diversão e ao encantamento de um jogo, 
tem-se uma excelente ferramenta educacional (AMARAL; SILVA; PANTALEÃO, 2015). As mídias digitais representam uma transformação significativa na forma como os jovens aprendem e produzem conhecimentos, ou seja, usados de forma adequada, jogos, competições e desafios permitem aumentar a motivação para 0 aprendizado, e tornar o processo de aprendizagem leve e agradável. O uso de competições deixam as atividades mais excitantes para os estudantes, levando-os a quebrar suas próprias barreiras no processo de aprendizagem (SANTOS et al., 2015; MATTAR, 2010).

A escolha pelo Robocode como ferramenta de estudo, foi feita devido às referências encontradas em vários trabalhos como Woolley e Peterson (2009), Harper (2011), O'Kelly e Gibson (2006), Liu (2008), Bonakdarian e White (2004).

O presente artigo tem como objetivo descrever uma experiência do uso da ferramenta Robocode no apoio ao ensino de programação, a fim de estimular o interesse em programação pelos alunos do curso de Sistemas de Informação do Instituto Federal de Goiás.

O artigo está organizado nas seguintes seções. Além desta introdução. A seção 2 faz uma explanação sobre as principais características da ferramenta Robocode. A seção 3 aborda a metodologia utilizada no desenvolvimento das atividades propostas. A seção 4 apresenta resultados alcançados e a experiência com o projeto. Por fim, na seção 5 são apresentadas as considerações finais e as perspectivas de trabalhos futuros.

\section{REVISÃO BIBLIOGRÁFICA}

Segundo Martins (2014), o Robocode é um jogo de programação, onde o objetivo é desenvolver um tanque de guerra de robô para a batalha contra outros tanques em uma arena virtual utilizando a linguagem de programação Java. Sendo assim, além de ser um jogo de programação, o Robocode também é usado para aprender a programar. Escolas e universidades estão usando Robocode para auxiliar o ensino de programação assim como para estudar inteligência artificial (IA), por meio de sua biblioteca de classes. O conceito do Robocode é fácil de entender, e uma maneira divertida de aprender a programar.

No Robocode o programador deve escolher a melhor estratégia para o seu robô, podendo manipular eventos que ocorrem durante a luta como evitar o impacto contra uma parede ou desviar das balas do adversário. As batalhas entre os robôs consistem de um ou vários rounds, na qual os robôs partem de uma posição inicial aleatória e têm de lutar uns contra os outros, 
individualmente ou em equipes (MARTINS, 2015)

Os usuários do ambiente têm acesso a um tutorial introdutório e a uma completa API Robocode. O sistema integra um editor e compilador como parte do ambiente Robocode. Um modelo para novos tanquesrobô é fornecido (BONAKDARIAN E WHITE, 2004).

No Robocode os robôs batalham até a morte em uma arena. A batalha consiste em um número predeterminado de rodadas, sendo o vencedor da batalha o robô com mais pontos. A rodada termina quando resta somente um robô sobrevivente dessa rodada. Os robôs começam com um nível de energia de 100 e morre quando a energia nível cai abaixo de zero. Os robôs estão equipados com radar, que podem varrer outros robôs até uma distância de 1200 pixels de distância. $O$ radar retorna informações sobre o robô, tais como, distância, posição, velocidade, nome e energia (GADE, 2003).

O robô é formado por corpo, radar e arma, podendo girar 360 graus cada parte independente umas das outros. A arma pode disparar com potência variável e aquece quando ela é acionada. Um robô tem que esperar a arma esfriar antes de outro tiro poder ser disparado, e a bala viaja mais rápido quando acionado com baixo consumo de energia. Se dois robôs colidem, ambos perdem 0,6 pontos de energia. Todas as batalhas são executadas em uma arena retangular de variável tamanho. O tamanho padrão é de $800 \times 600$ pixels, já os robôs têm um tamanho de $36 \times 45$ pixels. A velocidade máxima de um robô é de 8 pixels por segundos (GADE, 2003).

Durante o jogo, o robô deve navegar em torno do ambiente, evitando as paredes, balas disparadas pelos tanques e os outros tanques. Ao mesmo tempo, deve localizar o outro tanque, antecipar a sua posição provável. Programas com estratégias simples são fornecidos como amostra, para ajudar o programador novato a começar com o Robocode. Além disso, existem vários recursos na internet ilustrando estratégias avançadas (HARPER, 2011).

Os robôs são criados como uma nova classe Java. Os objetos robô tem um método de execução com um loop infinito que descreve o comportamento padrão para o robô. Além disso, outros métodos são invocados em resposta a eventos. As respostas incluem comandos como ahead(distance), back(distance), turnLeft(degrees), turnRight(degrees), fire(strength), turnGunLeft(degrees), entre outros (HARTNESS, 2004, KENSLER E AGAH, 2009).

No ambiente do Robocode conforme a Figura 1 é possível criar uma arena e configurar a batalha adicionando os robôs. 


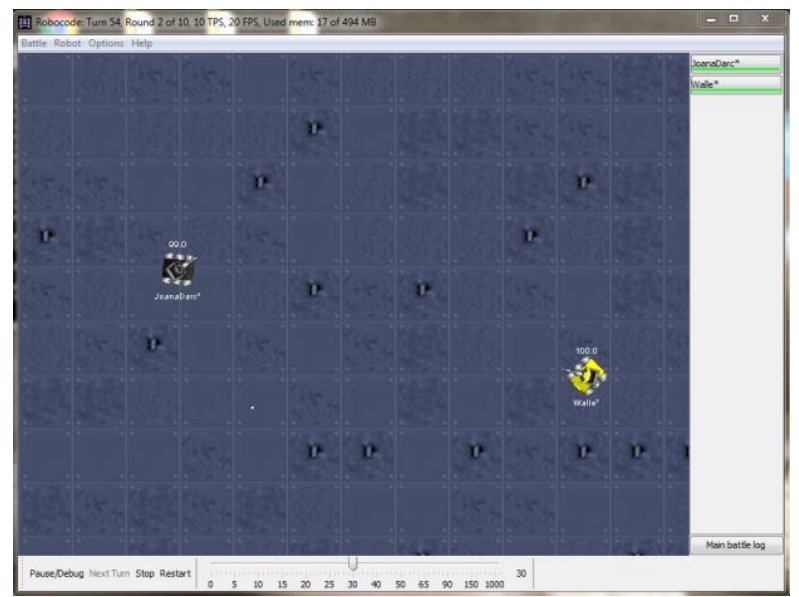

Figura 1. Tela principal do ambiente virtual do Robocode

Fonte: Própria.

A interatividade com o usuário é programada através de eventos para tratamento do mouse e teclado. Além disso, existem eventos para avisar ao robô quando ele acerta um tiro no adversário ou é acertado, quando ele é eliminado da batalha, ou quando ela é finalizada (LIMA et al., 2014).

O ambiente contém um editor de código-fonte próprio para programar os robôs conforme a Figura 2.

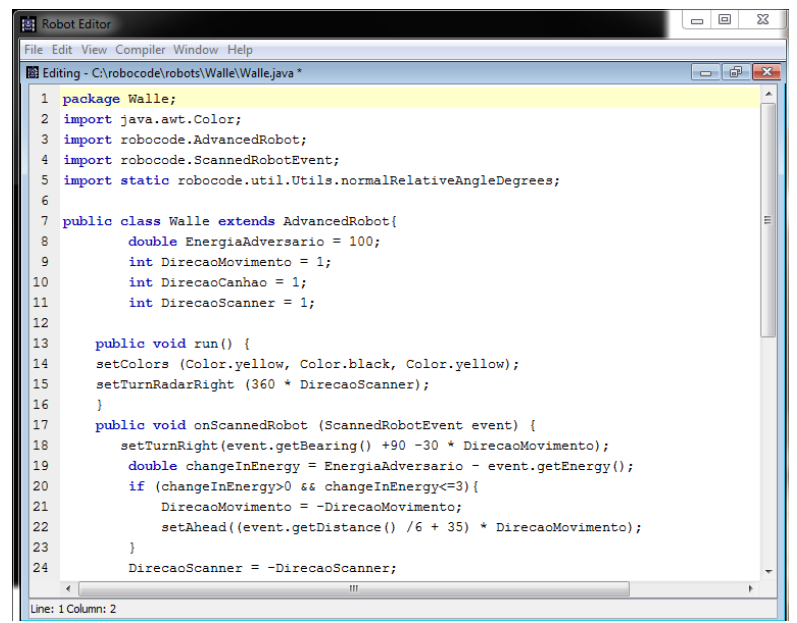

Figura 2. Editor de código-fonte do Robocode

Fonte: Própria.
A logica dos robôs no Robocode esta concentrada em métodos, que definem as ações e os movimentos dos robôs. Além disso, a movimentação dos robôs e algumas ações, como atirar em outros robôs, baseiam-se na definição de ângulos préespecificados, ou seja, requer a aplicação direta de conceitos matemáticos. Pode-se alterar: a direção de rotação do robô e do canhão, que podem ser movimentados para a direita ou esquerda, individualmente ou em conjunto; direção de movimentação, podendo ir para frente ou para trás; além das características relacionadas à bala, podendo alterar seu poder de fogo, direção e velocidade (AMARAL; SILVA; PANTALEÃO, 2015).

Existem na literatura diversos trabalhos sobre o Robocode, tais como:

Czajkowski e Patan (2009), que relataram tarefas de controle da torre em agentes do Robocode. Onde é realizada a tentativa de prever a posição do inimigo, através de suas últimas posições, para realizar o disparo.

Liu (2008), que descreveu uma experiência de utilização de Robocode durante três semanas com 26 estudantes de graduação. Relata que o uso de Robocode retrata situações realísticas, o que motiva os participantes. Também reporta que a necessidade exploratória e de 
autoaprendizagem é bastante presente em relatos feitos pelos estudantes.

O'Kelly e Gibson (2006), que fizeram uso da Aprendizagem Baseada em Problemas (Problem-Based Learning - PBL), aplicada para estudantes de graduação, com o objetivo de desenvolver batalhas com os robôs implementados pelos estudantes de forma a retratar a realidade em um âmbito profissional competitivo. Para tanto, foram montadas equipes, visto que é comum a programação em pares. Os vencedores participaram de uma batalha em esfera nacional, motivando o espírito competitivo dos estudantes. A metodologia PBL enfatiza o aprendizado autodirigido, centrado no estudante.

\section{METODOLOGIA}

O método de pesquisa adotado foi o estudo de caso. Yin (2005) diz que o estudo de caso é um tipo de pesquisa empírica que investiga um fenômeno contemporâneo dentro de seu contexto de vida real.

Esse artigo apresenta a experiência na realização do campeonato de Robocode no Instituto Federal de Goiás no ano de 2015. O evento foi realizado com sucesso. Os três primeiros colocados foram premiados com pontos extras na disciplina de Programação II.

Para a realização do campeonato foi disponibilizado um edital com informações tais como: objetivos, forma de inscrição, entrega dos robôs, regras do campeonato, premiação, e cronograma.

O campeonato foi realizado como atividade complementar com duração de oito horas, tendo como participantes alunos matriculados na disciplina de programação ॥ do curso superior em Sistemas de Informação, formando-se equipes com no máximo três alunos.

Duas semanas antes da realização do campeonato de Robocode foi oferecido e realizado um minicurso de Robocode com duração de duas horas no evento Software Freedom Day ministrado pelo professor da disciplina, tendo como objetivo apresentar e ensinar aos alunos participantes como preparar seus robôs para a competição.

Ao final da competição foram realizadas entrevistas, através de questionários semiestruturados. Participaram da pesquisa 15 (quinze) alunos da disciplina de programação II, do curso superior em Sistemas de Informação do Instituto Federal de Goiás.

\section{RESULTADOS}

Ao final do último dia dos campeonatos, os alunos responderam a um formulário de perguntas que avaliaram a eficiência deste em relação a despertar interesse ou reforçar a aprendizagem dos 
alunos no curso de Sistemas de Informação, levando-os a permanecer no curso.

Como resultados são apresentados na Tabela 1 às perguntas do formulário e as respostas em percentuais dos alunos do curso superior em Sistemas de Informação participantes do campeonato de Robocode 2015.

Tabela 1. Questionário com as respostas dos alunos

\begin{tabular}{|l|c|c|}
\hline \multicolumn{1}{|c|}{ QUESTÕES } & \multicolumn{2}{|c|}{2015} \\
\cline { 2 - 3 } & Sim & Não \\
\hline $\begin{array}{l}\text { Você ficou interessado em } \\
\text { programação através deste } \\
\text { campeonato de Robocode? }\end{array}$ & $95 \%$ & $0,5 \%$ \\
\hline $\begin{array}{l}\text { O campeonato de Robocode } \\
\text { deixou mais fácil o } \\
\text { entendimento em } \\
\text { programação? }\end{array}$ & $89 \%$ & $11 \%$ \\
\hline $\begin{array}{l}\text { O campeonato de Robocode } \\
\text { lhe motivou em aprender mais } \\
\text { sobre programação? }\end{array}$ & $92 \%$ & $0,8 \%$ \\
\hline $\begin{array}{l}\text { Você já conhecia o software } \\
\text { Robocode antes do } \\
\text { campeonato de Robocode? }\end{array}$ & $0,3 \%$ & $97 \%$ \\
\hline $\begin{array}{l}\text { Você gostaria que este tipo } \\
\text { de atividade fosse realizado } \\
\text { novamente? }\end{array}$ & $100 \%$ & $0 \%$ \\
\hline
\end{tabular}

Fonte: Própria.

Verificou-se a partir das respostas do questionário apresentadas na Tabela 1 , que mais de $90 \%$ dos alunos afirmam que aumentou $\mathrm{o}$ interesse dos mesmos por programação após a realização do campeonato de Robocode. Mais de $80 \%$ dos alunos relatam que o campeonato de Robocode deixou mais fácil o entendimento em programação. Mais de $90 \%$ dos alunos afirmam que o campeonato de Robocode motivou a aprender mais sobre programação. Quase $100 \%$ dos alunos dizem não conhecer o software antes do campeonato de Robocode. E todos os alunos participantes do campeonato de Robocode concordam que esta atividade deve ser realizada novamente.

Perguntados por que esta atividade deveria ser realizada novamente. Assim se manifestaram os alunos:

"para os alunos mostrarem suas habilidades em programação.".

"pois auxilia um pouco na compreensão da matéria.".

“Porque trás a possibilidade de adquirir novas experiências e incentiva o trabalho em equipe.".

"por que é uma atividade dinâmica e ajuda na matéria.".

“É uma atividade complementar que ajuda na integração dos alunos.".

"porque ajuda no conhecimento de novas formas de programação.".

“porque dessa forma é agregado mais conhecimento ao nosso currículo. No âmbito acadêmico somos motivados a pensar, pesquisar e sermos pessoas mais curiosas.".

Para confirmar ainda mais a eficiência do projeto, foi apresentado o numero de alunos matriculados, reprovados, a porcentagem de alunos reprovados e aprovados e à média do número de aprovados na disciplina de programação II do ano anterior em que não houve participação 
dos alunos do curso superior no campeonato de Robocode e comparados com os mesmos dados do ano de 2015 em que os alunos do curso superior participaram. Conforme mostra a Tabela 2.

Tabela 2. Porcentagem de alunos aprovados, reprovados e media da turma

\begin{tabular}{|c|c|c|c|c|c|}
\hline \multicolumn{7}{|c|}{ Disciplina de Programação II } \\
\hline Ano & Matriculados & Reprovados & $\begin{array}{c}\text { \% de } \\
\text { Reprovação }\end{array}$ & $\begin{array}{c}\text { \% de } \\
\text { Aprovação }\end{array}$ & $\begin{array}{c}\text { Media da } \\
\text { Turma }\end{array}$ \\
\hline 2014 & 17 & 12 & 70,58 & 29,42 & 3,87 \\
\hline 2015 & 15 & 7 & 46,66 & 53,34 & 5,93 \\
\hline
\end{tabular}

Fonte: Própria.

Conforme a tabela 2 , mais de $70 \%$ dos

alunos da turma de programação II de 2014 reprovaram na disciplina. Em contrapartida em 2015 com a participação dos alunos do curso superior no campeonato de Robocode a reprovação foi menos de $50 \%$. Este resultado sugere fortemente que o Robocode foi eficaz na promoção da aprendizagem.

Para realizar a comparação das medias utilizou-se $o$ teste $t$ com amostras independentes. $\mathrm{O}$ teste $\mathrm{t}$ é $\mathrm{O}$ método estatístico mais utilizado para se avaliar as diferenças entre as médias de dois grupos. Os resultados obtidos com a ferramenta Action são dados na figura 3 a seguir.

\begin{tabular}{cc}
\hline Informação & Valor \\
\hline T & $-1,804125482$ \\
Graus de Liberdade & 4 \\
P-valor & 0,145538174 \\
Média no grupo 1: & 3,866666667 \\
Média no grupo 2: & 5,933333333 \\
& \\
Desvio padrão amostral do grupo 1: & 1,650252506 \\
Desvio padrão amostral do grupo 2: & 1,101514109 \\
Desvio padrão agrupado: & 1,402973034 \\
& \\
Hipótese Alternativa: Diferente de & 0 \\
Intervalo de Confiança & $95 \%$ \\
& \\
Limite Inferior & $-5,247147519$ \\
Limite Superior & 1,113814185 \\
\hline
\end{tabular}

Figura 3. Resultado do Teste $t$ com amostras independentes
Fonte: Própria.

Observa-se na Tabela 2 e Figura 3 que no ano anterior a média da disciplina de programação II (grupo 1), foi de 3,87. Já com a participação no campeonato de Robocode, a média da disciplina de programação ॥ (grupo 2), foi de 5,93. Reforçando ainda mais a sugestão de que a ferramenta Robocode aplicada na promoção da aprendizagem realmente é eficaz.

O baixo rendimento acadêmico na disciplina de programação pode ser uma das principais causas da evasão no curso de Sistemas de Informação e retenção de alunos no semestre. A partir desse Estudo de Caso, foi possível observar o potencial do ambiente Robocode como ferramenta lúdica facilitadora do processo de ensinoaprendizagem, podendo ser utilizada como ferramenta para professores que ministram este tipo de disciplina. 


\section{CONSIDERAÇÕES FINAIS}

A atividade aplicada e desenvolvida no presente artigo facilita o ensino e a aprendizagem dos alunos e incentiva sua permanência no curso.

O Robocode permitiu aos alunos aplicar os conhecimentos de Programação Orientada a Objetos, estimular a criatividade e a participação em trabalhos em grupo, colocar em prática o que é estudado e abordado dentro das salas de aula, estimular a criatividade e aceitação de novos desafios explorando trabalho em equipe e competitividade.

Observou-se que as atividades envolvendo a programação do software Robocode são válidas para aqueles que desejam aprender ou aprimorar seus conhecimentos em programação. A realização do campeonato de Robocode deixou os alunos motivados a continuarem no curso, reduziu o número de reprovações na disciplina de programação e reduziu a evasão no curso de Sistemas de Informações.

O Robocode deixou a programação mais divertida, pois é efetuada através da criação de robôs para combate em uma arena virtual, mas através de uma atividade pratica do mundo real. Observou-se ainda o desenvolvimento de novas habilidades e raciocínio logico, capacidade, aprimoramento do conhecimento, incentivo e motivação aos estudos e trabalho em equipe.
Por fim o que foi abordado neste trabalho pode auxiliar estudantes e professores da área de programação, pois abordou vários conceitos importantes para esta área e que podem servir como base para o desenvolvimento de trabalhos futuros.

Como sugestão para trabalhos futuros sugere-se a aplicação deste estudo em um numero mais expressivo de alunos dos cursos superiores em diferentes campus ou instituições e o uso de mais ferramentas livres como o Robocode.

\section{REFERÊNCIAS}

AMARAL, A. L. As eternas encruzilhadas: de como selecionar caminhos para a formação do professor de ensino superior. In: ENDIPE, 22., 2004, Curitiba. Anais... Belo Horizonte: Ed. Universitária Champangnat, v. 1, p. 139150, 2004.

AMARAL, L; SILVA, G. B. E; PANTALEÃO, E. Plataforma Robocode como Ferramenta Lúdica de Ensino de Programação de Computadores - Pesquisa e Extensão Universitária em Escolas Públicas de Minas Gerais. In: SIMPÓSIO BRASILEIRO DE INFORMÁTICA NA EDUCAÇÃO, 26. Anais... Maceió, $2015 . \quad$ p. 200. https://doi.org/10.5753/cbie.sbie.2015.200

BITTENCOURT, R. A. et al. Aprendizagem de Programação Através de Ambientes Lúdicos em um Curso de Engenharia de Computação: Uma Primeira Incursão. In: WORKSHOP SOBRE EDUCAÇÃO EM COMPUTAÇÃO, 21. Anais... 2013. p. 749-758.

BONAKDARIAN, E.; WHITE, L. Robocode throughout the curriculum. Journal of Computing Sciences in Colleges, v.19, n.3, p.311-313, 2014. 
CZAJKOWSKI, A.; PATAN, K. Real-Time Learning of Neural Networks and its Application to the Prediction of Opponent Movement in the Robocode Enviroment. In: INTERNATIONAL PHD WORKSHOP. CONFERENCE ARCHIVES, 11. Anais... 2009.

DIAS, K. L.; SERRAO, M. S. A Linguagem Scratch no Ensino de Programação: Um Relato de Experiência com Alunos Iniciantes do Curso de Licenciatura em Computação. In: Workshop sobre Educação em Computação. Sistemas Sociais e Eventos de Grandes Massas: Ampliando Desafios da Computação, 22. Anais... 2014.

FRANÇA, R. S.; SILVA, W. C; AMARAL, H. J. C. Computino: um jogo destinado à aprendizagem de Números Binários para estudantes da educação básica. In: CONGRESSO DA SBC- WEI, 33. Anais... Maceió, 2013.

FREITAS, R. L.; PIVA JR, D. Estratégias para melhorar os processos de Abstração na disciplina de Algoritmos. In: WORKSHOP SOBRE EDUCAÇÃO EM COMPUTAÇÃO. 19. Anais... Natal, 2011.

GADE, M. et al. Applying Machine Learning to Robocode. JSK, Aalborg, 2003.

HARPER, R. Co-evolving Robocode tanks. In: ANNUAL CONFERENCE ON GENETIC AND EVOLUTIONARY COMPUTATION, 13., Proceedings... New York, USA, 2011. p.14431450.

https://doi.org/10.1145/2001576.2001770

HARTNESS, K. Robocode: using games to teach artificial intelligence. Journal of Computing Sciences in Colleges, v.19, n.4, p.287-291, 2004.

KENSLER, J. A.; AGAH, A. Neural networksbased adaptive bidding with the contract net protocol in multi-robot systems. Applied Intelligence, v. 31, n.3, 2009. https://doi.org/10.1007/s10489-008-0131-1

LIMA, A. F. et al. Robótica Educacional Utilizando Robocode como Ferramenta de Ensino para Diminuir a Evasão de Alunos no Curso de Engenharia Elétrica. In: CONGRESSO
BRASILEIRO DE ENSINO EM ENGENHARIA. Anais... Juiz De Fora - MG, 2014.

LIU, P. L. Using open-source Robocode as a Java programming assignment. SIGCSE Bull, n.40, v.4, p.63-67, 2008. https://doi.org/10.1145/1473195.1473222

LOBO ROBERTO, et al. A Evasão no Ensino Superior Brasileiro. Caderno de Pesquisa do Instituto Lobo para o Desenvolvimento da Educação, da Ciência e da Tecnologia. São Paulo, v. 37, n. 132, p. 641-659, 2007.

LONG, J. Just for fun: using programming games in software programming training and education - a field study of ibm robocode community. Journal of Information Technology Education, v. 6, p-279-290, 2007.

MARTINS, E. R. Utilização do Robocode como Ferramenta de Auxilio ao Ensino de Programação Orientada a Objeto. In: II Escola Regional de Informática de Goiás, 2. Anais... Goiânia: Gráfica UFG, v. 1. p.183-188, 2014.

MARTINS, E. R. Utilização do Robocode como Ferramenta de Auxílio ao Ensino de Programação Orientada a Objeto na Disciplina de Programação para Web. Revista Técnica e Tecnológica: Ciência, Tecnologia, Sociedade, v. 1, p. 1-8, 2015.

MATTAR, J. Games em educação: como os nativos digitais aprendem. São Paulo: Pearson Prentice Hall, 2010.

MORAN, J. M. Integração das tecnologias na educação. In: Salto para o futuro. Brasília: Posigraf, 2005.

MORAN, J. M. A educação que desejamos: novos desafios e como chegar lá. 4. ed. São Paulo: Papirus, 2009.

MORAN, J. M.; MASETTO, M. T.; BEHRENS, M. A. (Ed.). Novas tecnologias e mediações pedagógicas. 13. ed. São Paulo: Papirus, 2007.

O'KELLY, J.; GIBSON, J. P. RoboCode \& problem-based learning: a non-prescriptive approach to teaching programming. SIGCSE Bull, v.3, n.38, p.217-221, 2006. https://doi.org/10.1145/1140123.1140182 
SANTOS, C. S. et al. Aprendendo Programação Orientada a Objetos com uma Abordagem Lúdica Baseada em Greenfoot e Robocode. In: CONGRESSO BRASILEIRO DE EDUCAÇÃO EM ENGENHARIA, 43. Anais... 2015.

SAVI, R.; ULBRICHT, V. R. Jogos digitais educacionais: benefícios e desafios. RENOTE - Revista Novas Tecnologias na Educação, v.6, n. 2, p.1-10, 2008.

WOOLLEY, B. G.; PETERSON, G. L. Unified behavior framework for reactive robot control. Journal of Intelligent and Robotic Systems, v.55, n.2-3, p.155-176, 2009. https://doi.org/10.1007/s10846-008-9299-1

YIN, R. K. Estudo de caso: planejamento e métodos. Porto Alegre: Bookman, 2005. 